Article

\title{
Surface Roughness-Governed Shape Stability of the Coal Fly Ash-Based Phase Change Material: Molten Salt Processing and Thermal Properties
}

\author{
Denian Li ${ }^{1,2,3}$, Jizhang Yang ${ }^{1,2,3}$, Menglei Chang ${ }^{4}$, Yue Zhao ${ }^{1,2,3,5}$, Haoran Yuan ${ }^{1,2,3, *}$ and Yong Chen ${ }^{1,2,3}$ \\ 1 Laboratory of Integrated Technology for "Urban and Rural Mines" Exploitation, Guangzhou Institute of \\ Energy Conversion, Chinese Academy of Sciences, No.2 Nengyuan Road, Wushan, Tianhe District, \\ Guangzhou 510640, China; lidn@ms.giec.ac.cn (D.L.); jizhyang137@126.com (J.Y.); \\ 1507zhaoyue@whut.edu.cn (Y.Z.); chenyong@ms.giec.ac.cn (Y.C.) \\ 2 Southern Marine Science and Engineering Guangdong Laboratory (Guangzhou), Guangzhou 511458, China \\ 3 Guangdong Provincial Key Laboratory of New and Renewable Energy, Chinese Academy of Sciences, \\ Guangzhou 510640, China \\ 4 School of Materials and Energy, Foshan University, Foshan 528225, China; mengleic@sina.com \\ 5 School of Materials Science and Engineering, Wuhan University of Technology, Wuhan 430070, China \\ * Correspondence: yuanhr@ms.giec.ac.cn
}

Citation: Li, D.; Yang, J.; Chang, M.; Zhao, Y.; Yuan, H.; Chen, Y. Surface Roughness-Governed Shape Stability of the Coal Fly Ash-Based Phase Change Material: Molten Salt Processing and Thermal Properties. Energies 2021, 14, 1427. https:// doi.org/10.3390/en14051427

Received: 24 January 2021

Accepted: 2 March 2021

Published: 5 March 2021

Publisher's Note: MDPI stays neutral with regard to jurisdictional claims in published maps and institutional affiliations.

Copyright: (c) 2021 by the authors. Licensee MDPI, Basel, Switzerland. This article is an open access article distributed under the terms and conditions of the Creative Commons Attribution (CC BY) license (https:// creativecommons.org/licenses/by/ $4.0 /)$.

\begin{abstract}
Coal fly ash (FA) valorization is of great significance and sustainable interests to addressing the current environmental challenges faced by coal power industry. Herein, this work attempted a novel molten salt $\mathrm{Na}_{2} \mathrm{CO}_{3}$ treatment for processing FA into a robust matrix to support lauric acid (LA) toward construction of latent phase change composite. Their micromorphology, physiochemical, and thermal properties were monitored with scanning and transmission microscopy, $\mathrm{X}$-ray diffraction and

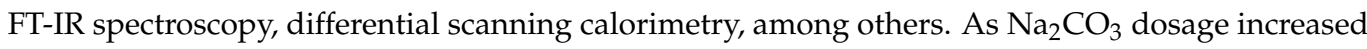
from $20 \%$ to $40 \%$, the FA experienced firstly higher loss of $\mathrm{SiO}_{2}$ and then substantial loss of $\mathrm{Al}_{2} \mathrm{O}_{3}$, and yet exhibited merely varied porosity. Then, both the composites revealed a maximum LA content of $20 \%$ that doubled that of pristine FA. Nevertheless, the optimal composite was disclosed with thermal conductivity of $0.5668 \mathrm{~W} / \mathrm{mK}$, which was $69 \%$ higher than its FA-based counterpart. It was proposed that the surface roughness evidenced by the formation of tremendous grooves and gaps during thermal alkaline processing were accountable for the promoted carrying capacity toward organic component. Furthermore, the latent phase change composite revealed excellent durability, including negligibly varied phase transition temperature and enthalpy even after 1500 thermal cycling, which promised great interest in passive building cooling. Meanwhile, the finds here led to a new understanding into the structural origin of adsorption capacity by inorganic FA, and may provide guidance for better exploration of its characteristics for other applications.
\end{abstract}

Keywords: fly ash; molten salts; surface roughness; enhanced thermal conductivity; phase change material

\section{Introduction}

Coal accounts for over $85 \%$ of China's primary energy reserves, and coal power offers over $60 \%$ in total energy supply each year in China. Fly ash (FA), as a well-known byproduct of coal power plants that is mostly constituted of $\mathrm{SiO}_{2}$ and $\mathrm{Al}_{2} \mathrm{O}_{3}$, had therefore become one of the most produced solid wastes in bulk [1]. Conventional disposal including dumping or burial imposed great threat over surroundings and public health. Thus, to find a rational way of utilization at large scale is critically important to address the above issues. Given its inorganic nature, FA shows great promise for constructing materials [2,3]. Nevertheless, it was mainly used as structural or additive components. Exploration of FA-based materials with designed functionalities by full exploitation of its physiochemical feature is of continuous interest for valorization of this kind of solid waste. 
The currently increasing worldwide concerns over global climate and environment changes has especially driven tremendous efforts into the improvement of energy conversion and utilization efficiencies. In particular, the building energy consumption was estimated to be as high as 33\% of annual total social energy consumption in China. With decent energy storage density, customizable thermal properties, and flexible applicability, latent phase change material therefore received great interest for passive building energy conservation and solar energy storage systems, among others [4,5]. By virtue of the high latent heat, near ambient phase transition temperature, excellent thermal, volumetric, and chemical stability, and negligible vapor pressure, lauric acid (LA) was widely used as an active component for constructing various kinds of phase change materials [6-8]. Meanwhile, to guarantee the reversible transition in practical use, the active components were usually integrated into a solid matrix, so far, expanded graphite, aerogels made up of graphene and carbon nanotubes [9,10], kaolin clay, diatomite [6,11], expanded perlite [12,13], mesoporous silica [14], $\mathrm{TiO}_{2}$ [15], etc., most of which possess considerable amount of diverse porosity and, to some extent, valuable products in many industries. The waste FA would be a competent candidate with regard to economic concerns, yet, its naturally poor carrying capacity strongly hindered the application as matrix for functional composites design. On the other hand, most of the previous work emphasizes the importance of matrix porosity, either naturally-occurring or post-created, in the latent phase change composite; while little attention has been given to potential of surface roughness, not mentioning its contribution to final thermal properties and stability $[16,17]$.

In this work, a novel molten salt $\mathrm{Na}_{2} \mathrm{CO}_{3}$ treatment was attempted for processing FA into a robust matrix to support lauric acid (LA) toward construction of latent phase change composite. The micromorphology, physiochemical, and thermal properties of a series of resultants was monitored with scanning and transmission microscopy, $\mathrm{X}$-ray diffraction and FT-IR spectroscopy, differential scanning calorimetry, among others. Interestingly, it was revealed that the surface roughness instead of porosity was responsible for the enhancement of adsorption capacity of modified FA (mFA), which enabled both the phase change enthalpy and excellent thermal durability. Along with the dramatically promoted thermal conductivity, the hybrid materials are promising for passive energy saving in building structures. Moreover, the finding here provided a further understanding of the carrying capacity of inorganic fly ash.

\section{Experimental}

\subsection{Materials and Chemical Reagents}

Commercial fly ash was purchased from Gongyi Filter Material Limited Company (Gongyi City, China). Lauric acid (LA) and sodium carbonate, both of analytical grade, were purchased from Shanghai Dibo biotechnology Limited Company (Shanghai City, China) and Tianjin Qilun Chemical Science and Technology Limited Company (Tianjin, China), respectively.

\subsection{Thermal Molten Salt Processing of Fly Ash}

The fly ash was modified by facile thermal processing with $\mathrm{Na}_{2} \mathrm{CO}_{3}$. The weight ratio of $\mathrm{Na}_{2} \mathrm{CO}_{3}$ to fly ash was from 0.2 to 0.4 . After adding $\mathrm{Na}_{2} \mathrm{CO}_{3}$, the mixture was loaded into a ceramic boat and subjected to $900{ }^{\circ} \mathrm{C}$ treatment. When naturally cooled to room temperature, the mixture was washed with distilled water, and the thermal alkalinemodified fly ash (mFA) was obtained after desiccation at $80^{\circ} \mathrm{C}$.

\subsection{Preparation of Phase-Change Composite Material (PCCM)}

The preparation of phase-change composite material (PCCM) followed a vacuumassisted impregnation method, as shown in Figure 1. Typically, the mixture of LA and FA with set ratio was fully mixed before being transferred into the vacuum drying oven, which was further vacuumed and elevated to $80^{\circ} \mathrm{C}$ for $1 \mathrm{~h}$. After then, the pressure was recovered. This operation was repeated three times to facilitate the adsorption of LA into FA matrix. 
Finally, the fresh PCCM was kept under the vacuum and $80{ }^{\circ} \mathrm{C}$ overnight before being naturally cooled to ambient temperature. The optimal ratio was determined by diffusion test. Namely, the composite was pressed into a column with height of $0.2 \mathrm{~cm}$ and diameter of $1.3 \mathrm{~cm}$, and then placed on top of a filter paper at $60^{\circ} \mathrm{C}$ for $1 \mathrm{~h}$. Thus, the leakage of LA can be visually observed by the color change from the paper. Finally, the optimum loading amount for FA, $0.2 \mathrm{mFA}$, and $0.4 \mathrm{mFA}$ were $10 \%, 20 \%$, and $20 \%$, respectively.
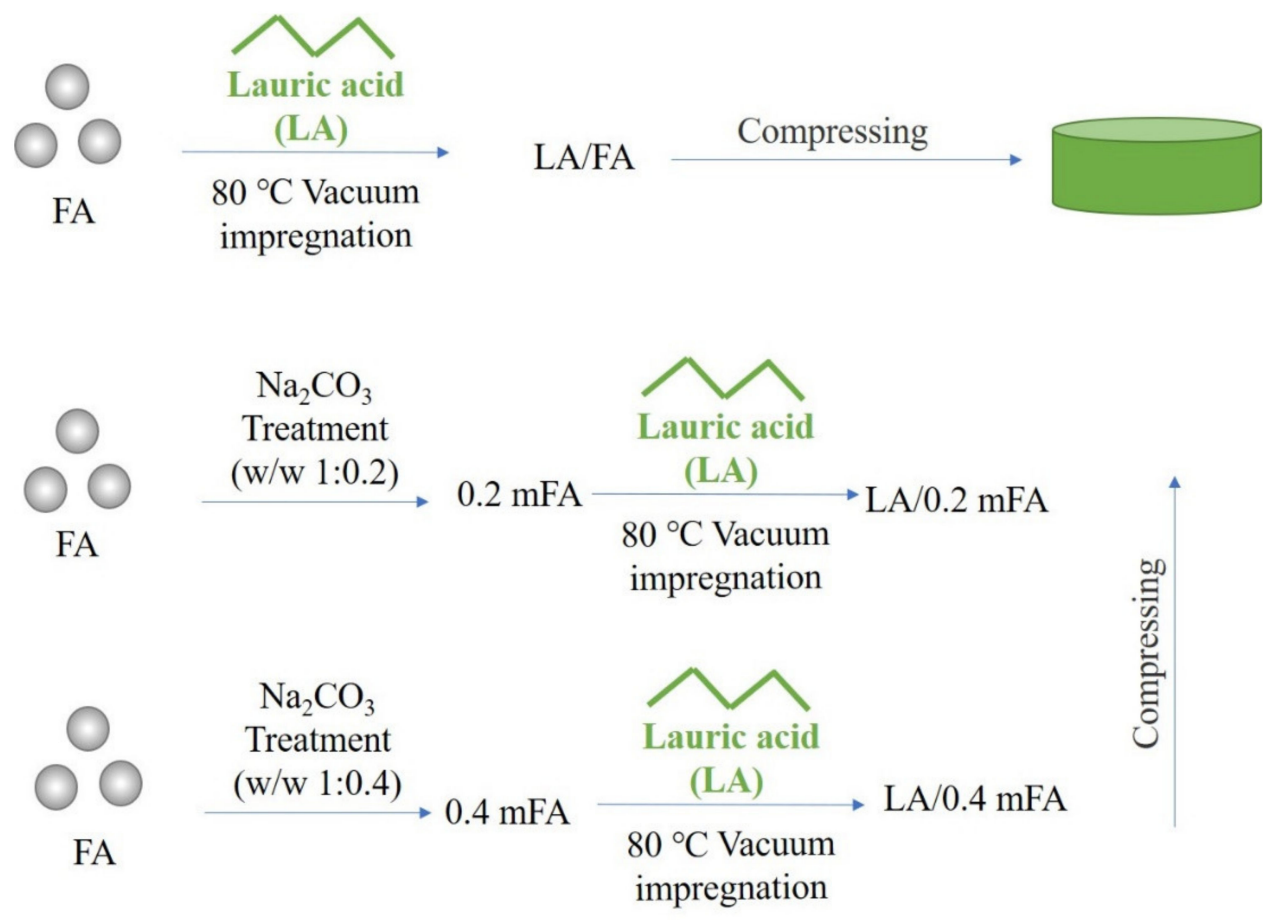

Figure 1. Block diagram of synthesis procedure.

\subsection{Characterizations}

The micromorphology was obtained with scanning electron microscopy (SEM, Hitachi S-4800, Japan). X-ray fluorescence (XRF) analysis was performed with analyzer from AxiosmAX Petro, Netherlands. Differential scanning calorimetry (DSC) profiles were recorded with low-temperature analyzer (HDS CPT500LT/1400, German). The $\mathrm{N}_{2}$ isothermal adsorption-desorption profiles were studied with the automated gas sorption analyzer (SI-MP-10, Quadrasorb, Quantachrome, USA) at $77 \mathrm{~K}$, while the specific surface area was obtained basing on the Brunauer-Emmett-Teller method. The thermal conductivity was tested by a TPS2500S/TPS2500S analyzer (Hot Disk, Sweden), and the corresponding test range was $0.005-1800 \mathrm{~W} /(\mathrm{mK})$. FT-IR spectra were acquired with FTIR TENSOR27 spectrometer.

\section{Results and Discussion}

Figure 2 depicts the brief preparative procedures of PCCMs. The pristine FA was fully mixed with a certain amount of $\mathrm{Na}_{2} \mathrm{CO}_{3}$ and subjected to heating treatment. After being cooled down, the resultant was washed with distilled water, and the mFA with reconstructed surface was obtained. After vacuum adsorption above molten point of LA, the PCCMs named LA $/ x$ mFA were then acquired, where $x$ is the weight ratio of $\mathrm{Na}_{2} \mathrm{CO}_{3}$ to FA. 


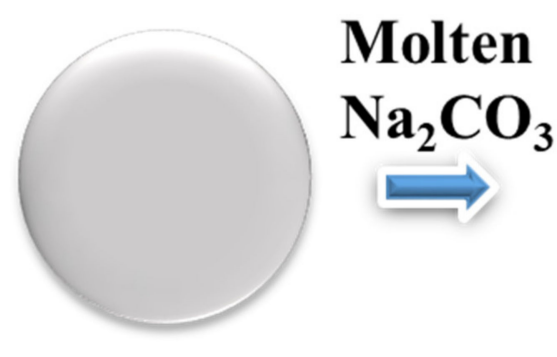

FA

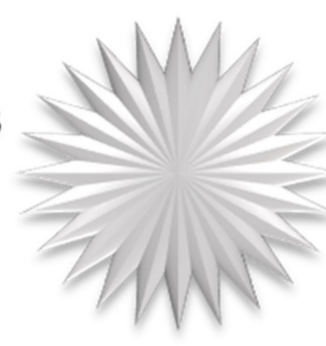

mFA
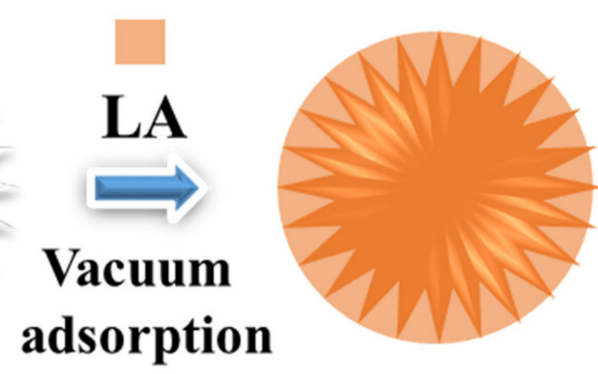

LA/xmFA

Figure 2. Schematic illustration of the composite preparation.

Figure 3 revealed the micromorphology of FA, $0.2 \mathrm{mFA}, 0.4 \mathrm{mFA}$, and their LA-loaded counterparts. In Figure 3a, the pristine FA was generally demonstrated as particulatedecorated microspheres, yet, the surface exposed around those particulates was quite smooth. After LA loading, many tiny particles emerged, accompanied by the appearance of irregular mass in between different microspheres (Figure 3b). Despite $\mathrm{Na}_{2} \mathrm{CO}_{3}$ processing at high temperature, the resultant $0.2 \mathrm{mFA}$ and $0.4 \mathrm{mFA}$ maintained their spherical body. Yet, both revealed significantly enhanced surface roughness. Furthermore, many chips-like structures were observed around the surface of $0.2 \mathrm{mFA}$, as shown in Figure $3 \mathrm{c}$, this can be ascribed to the strong etching effect by $\mathrm{Na}_{2} \mathrm{CO}_{3}$. By contrast, the LA/0.2 mFA had a relatively smoother surface. It is proposed that the vacuum loading process above melting point of LA could facilitate the organic fluid being well absorbed into the gaps under the chips, also filled into the grooves over the sphere. Finally, the surface seemed "repaired". In the case of $0.4 \mathrm{mFA}$, a similar situation was observed. The spheres in Figure $3 \mathrm{f}$ were wrapped with syncretic LA flakes.

The component variation during molten $\mathrm{Na}_{2} \mathrm{CO}_{3}$ treatment was monitored by XRF

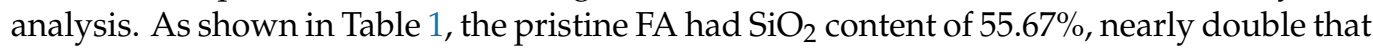
of $\mathrm{Al}_{2} \mathrm{O}_{3} \cdot \mathrm{Na}_{2} \mathrm{CO}_{3}$ is reactive to both the $\mathrm{SiO}_{2}$ and $\mathrm{Al}_{2} \mathrm{O}_{3}$. Therefore, with lower $\mathrm{Na}_{2} \mathrm{CO}_{3}$ dosage, more of the alkaline tended to react with $\mathrm{SiO}_{2}$ due to the higher content-offered contact opportunity. Thus, the relative proportion of $\mathrm{Al}_{2} \mathrm{O}_{3}$ to $\mathrm{SiO}_{2}$ actually increased from 0.5 to 0.54 . When higher $\mathrm{Na}_{2} \mathrm{CO}_{3}$ dosage was applied, this ratio dropped to 0.46 in the case of $0.4 \mathrm{mFA}$. Moreover, the XRD patterns of FA, $0.2 \mathrm{mFA}, 0.4 \mathrm{mFA}$, LA/0.2 mFA, LA/0.4 mFA, and LA are provided in Figure 4 . The noticeable peaks around $17.1^{\circ}, 22.4^{\circ}, 27.5^{\circ}$, and $33.8^{\circ}$ are attributable to characteristic signals of the mullite phase [18-22]. Meanwhile, the $\mathrm{SiO}_{2}$ was supposed to be primarily amorphous since no noticeable peak was revealed for quartz. By indexing with XRD standard card, the newly appeared peaks at $20.5^{\circ}, 21.3^{\circ}$, $23.2^{\circ}, 27.3^{\circ}$, and $29.4^{\circ}$ can be ascribed to the diffractions by $020,002,201,210$, and 202 plane in $\mathrm{NaAlSiO}_{4}$ [23-27]. The pure LA displayed two distinct peaks at $22^{\circ}$ and $24.5^{\circ}[18,28-31]$. Furthermore, the composite showed integrated diffraction patterns of modified fly ash and LA without newly appeared signals, suggesting the physical interactions were accountable for their combination. In addition, the LA dispersed in both $0.2 \mathrm{mFA}$ and $0.4 \mathrm{mFA}$ remained crystalline, this provided the basis for latent energy storage. To reveal the effect of molten salt processing on the porosity, nitrogen isothermal adsorption and desorption analysis was then performed, and the corresponding profiles of FA, $0.2 \mathrm{mFA}$, and $0.4 \mathrm{mFA}$ were plotted in Figure 5a. The three samples revealed generally the same adsorption and desorption behavior, and the specific surface area were found to be $0.7,0.6$, and $0.5 \mathrm{~m}^{2} / \mathrm{g}$, respectively, suggesting negligible changes. Meanwhile, the pore diameter are mostly below $40 \mathrm{~nm}$. 

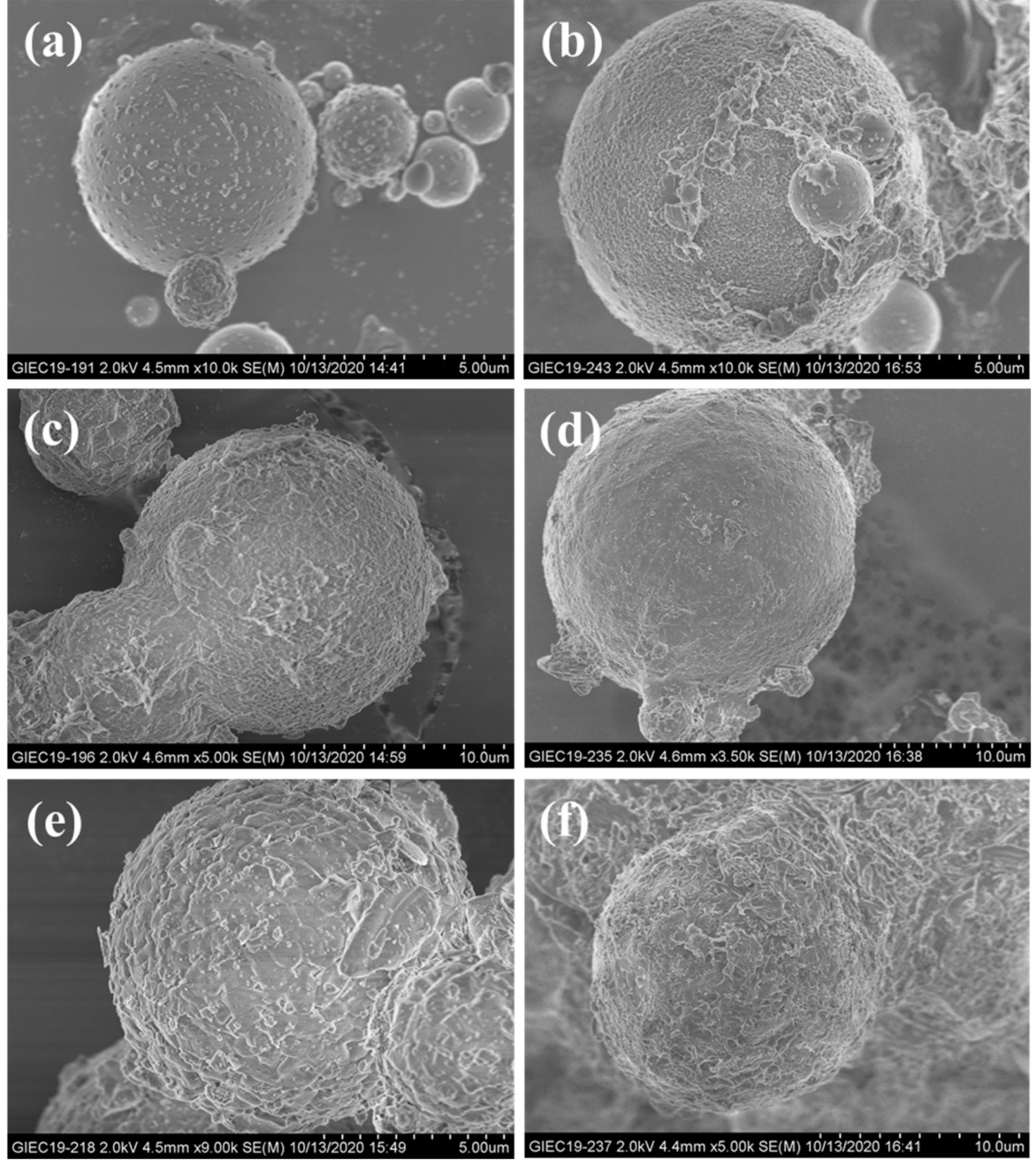

Figure 3. SEM images of: (a) fly ash (FA); (b) lauric acid (LA)/FA; (c) 0.2 modified fly ash (mFA0); (d) LA/0.2 mFA; (e) $0.4 \mathrm{mFA}$ and (f) LA/0.4 mFA.

Table 1. Components of FA and mFA by X-ray fluorescence (XRF) analysis.

\begin{tabular}{ccccccc}
\hline Compound & $\mathrm{SiO}_{\mathbf{2}}$ & $\mathrm{Al}_{\mathbf{2}} \mathbf{O}_{\mathbf{3}}$ & $\mathbf{C a O}$ & $\mathrm{Fe}_{\mathbf{2}} \mathbf{O}_{\mathbf{3}}$ & $\mathbf{N a}_{\mathbf{2}} \mathbf{O}$ & Others \\
\hline FA & 55.67 & 27.91 & 5.36 & 5.03 & 0.4 & 5.63 \\
$0.2 \mathrm{mFA}$ & 47.20 & 25.61 & 6.02 & 5.68 & 10.22 & 15.49 \\
$0.4 \mathrm{mFA}$ & 47.84 & 21.81 & 4.67 & 5.27 & 15.82 & 20.41 \\
\hline
\end{tabular}

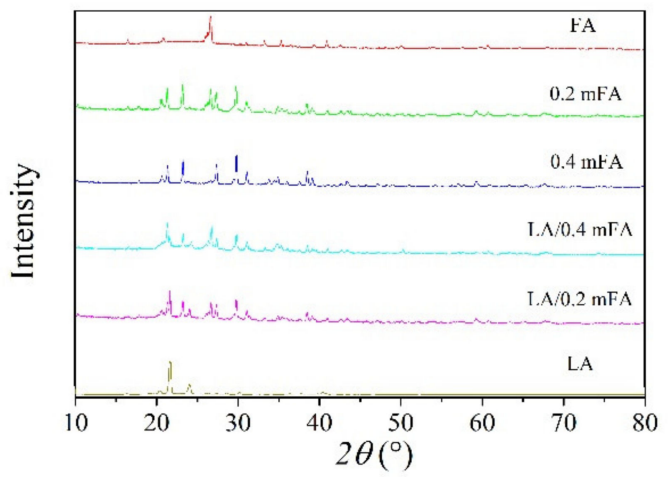

Figure 4. XRD patterns of FA, $0.2 \mathrm{mFA}, 0.4 \mathrm{mFA}, \mathrm{LA} / 0.2 \mathrm{mFA}$, and LA/0.4 mFA. 

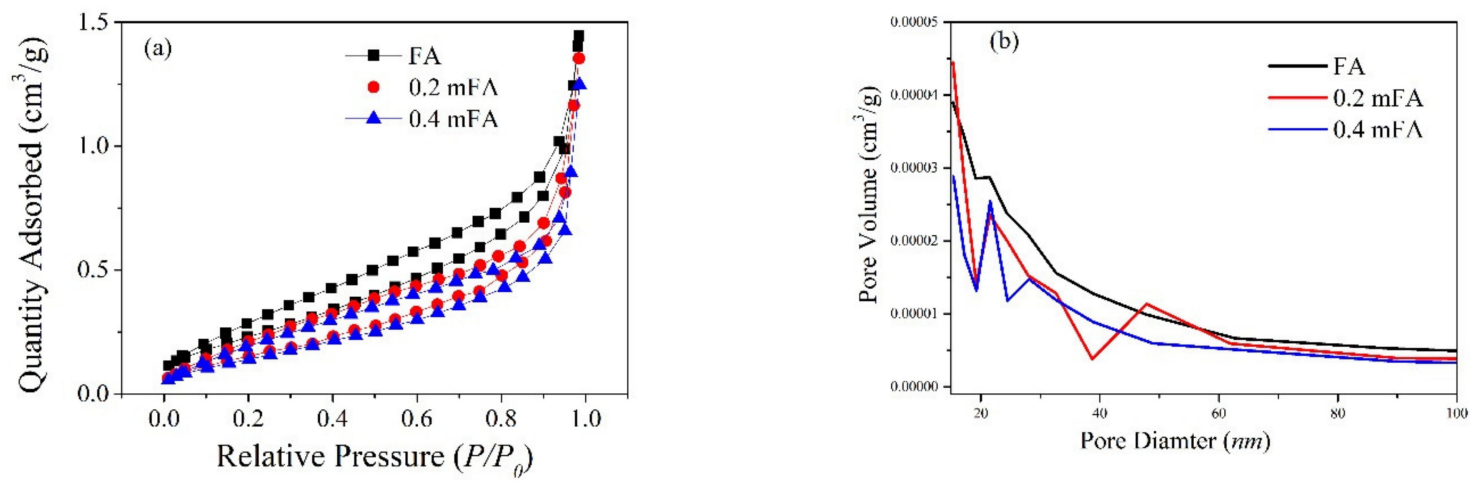

Figure 5. (a) Nitrogen isothermal adsorption and desorption profiles and (b) pore size distribution.

The chemical structures of bare FA and LA and the composites were characterized with FT-IR across a range of 500-4000 $\mathrm{cm}^{-1}$. As shown in Figure 6, the wide adsorption at $1102 \mathrm{~cm}^{-1}$ was ascribed to the characteristic stretching vibration of the Si-O bond [32-36]. This peak can be easily identified within the curves of both $0.2 \mathrm{mFA}$ and $0.4 \mathrm{mFA}$. The pure LA showed multiple characteristic adsorptions across in the range from 3000 to $1500 \mathrm{~cm}^{-1}$ [31,37-40]. Two of them located at 2918 and $2850 \mathrm{~cm}^{-1}$ were due to the stretching vibrations of $-\mathrm{CH}_{2}$ and $\mathrm{CH}_{3}$, whilst the one at $1695 \mathrm{~cm}^{-1}$ was attributable to the adsorption by carboxylic groups at the end of each molecule chain. All these featured peaks appeared in those composites, which suggested the successful loading of LA in the matrix. Furthermore, no new peak was found, therefore, the hybrid had formed in a physical manner, which is consistent with the result from above XRD analysis.

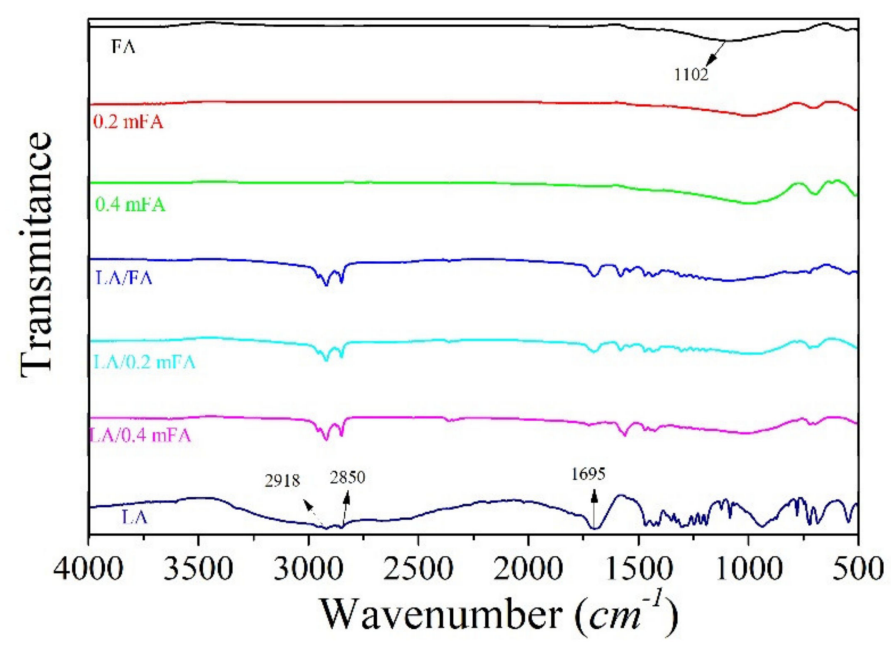

Figure 6. FT-IR spectra of FA, 0.2 mFA, 0.4 mFA, LA/0.2 mFA, LA/0.4 mFA, and LA.

Thermal conductivity is one of the most important factors for phase change composites. Herein, the thermal conductivity was then measured by a transient plane source method, where the samples were required to be shaped into cylinder. However, the attempt with FA failed due to the intrinsically poor interactions between those inorganic particulates. By contrast, the LA introduced into FA functioned as an adhesive and rendered the composite with benign moldability, and the thermal conductivity was then determined to be $0.3344 \mathrm{~W} / \mathrm{mK}$. Interestingly, even with higher loading of LA, both phase change composite with modified FA revealed significantly enhanced thermal conductivity. The value of LA/ $0.2 \mathrm{mFA}$ and LA/0.4 mFA were $0.5668 \mathrm{~W} / \mathrm{mK}$ and 0.5141 , which are $69 \%$ and $54 \%$ higher than that of the LA/FA. Given the structural transition revealed above, it was proposed that the relatively higher amount of residual $\mathrm{Al}_{2} \mathrm{O}_{3}$ in the matrix at lower dosage 
of molten $\mathrm{Na}_{2} \mathrm{CO}_{3}$ would provide more rapid thermal diffusion pathways. The higher loss of $\mathrm{Al}_{2} \mathrm{O}_{3}$ in $\mathrm{LA} / 0.4 \mathrm{mFA}$ therefore led to slightly decreased thermal conductivity, yet still higher than its unmodified counterpart.

DSC was further applied to disclose the texturally thermal storage capacity of LA and three phase change composites. Figure 7 showed their DSC profiles. All displayed obvious supercooling phenomenon. The melting and freezing points and corresponding phase change enthalpy $\left(\Delta H_{m}\right)$ was summarized in Table 2 . To be specific, the $T_{m}$ and $T_{c}$ for pure LA, LA/FA, LA/0.2 mFA, and LA/0.4 mFA were 43.1 and $40.3^{\circ} \mathrm{C}, 42.3$ and $38.5^{\circ} \mathrm{C}$, 39.5 and $32.1^{\circ} \mathrm{C}$, and 39.7 and $32.4^{\circ} \mathrm{C}$. Meanwhile, the freezing point showed evident decrease. As the solidification of LA followed typical crystallization manner, the rigid surface of FA may provide tremendous heterogeneous nucleus sites, which thus initiate the rearrangement of flexible LA molecule chains at lower temperature. After etching by molten salts, the surface became significantly rougher, thus the freezing point further decreased with LA/0.2 mFA and LA/0.4 mFA. Meanwhile, the reverse melting behavior also tended to occur at lower temperature. On top of that, the reinforced thermal conductive performance by inorganic structures may also facilitate the heat transfer in the composites. Finally, the phase change temperature window was well fitted with ambient temperature $\left(30-45^{\circ} \mathrm{C}\right)$. Therefore, such hybrid composite may function as active component for heat storage in passive energy-saving building structures, which help to reduce the indoor temperature amplitude.

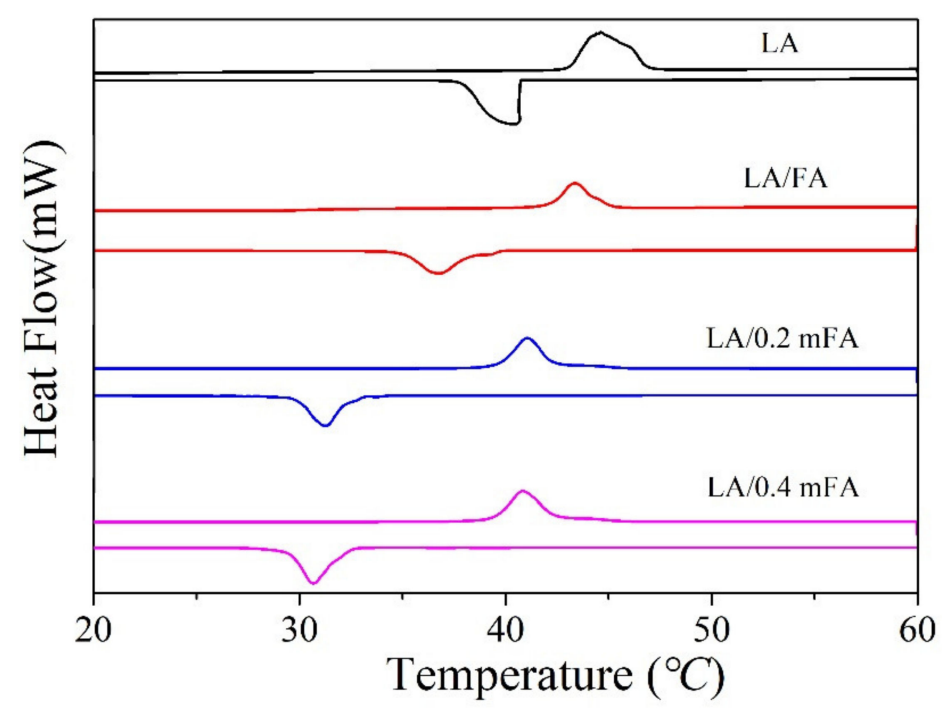

Figure 7. Differential scanning calorimetry (DSC) curves of LA, LA/FA, LA/0.2 mFA, and LA/0.4 mFA.

Table 2. Phase transition temperature and corresponding enthalpy.

\begin{tabular}{ccccc}
\hline \multirow{2}{*}{ PCM } & \multicolumn{2}{c}{ Heating Process } & \multicolumn{2}{c}{ Cooling Process } \\
& $\boldsymbol{T}_{\boldsymbol{m}}\left({ }^{\circ} \mathbf{C}\right)$ & $\boldsymbol{\Delta} \boldsymbol{H}_{\boldsymbol{m}}(\mathbf{J} / \mathbf{g})$ & $\boldsymbol{T}_{\boldsymbol{c}}\left({ }^{\circ} \mathbf{C}\right)$ & $\boldsymbol{\Delta} \boldsymbol{H}_{\boldsymbol{c}}(\mathbf{J} / \mathbf{g})$ \\
\hline LA & 43.1 & 186.6 & 40.3 & 183.5 \\
LA/FA & 42.3 & 16.7 & 38.5 & 15.8 \\
LA/0.2 mFA & 39.5 & 34.1 & 32.1 & 31.3 \\
LA/0.4 mFA & 39.7 & 31.5 & 32.4 & 27.6 \\
\hline
\end{tabular}

In the DSC process, the integration of endothermic and exothermic peak area generally tells phase change enthalpy. As listed in Table 2, the $\Delta H_{m}$ and $\Delta H_{c}$ for LA, LA/FA, LA/0.2 mFA, and LA/0.4 mFA were 186.6 and $183.5 \mathrm{~J} / \mathrm{g}, 16.7$ and $15.8 \mathrm{~J} / \mathrm{g}, 34.1$ and $31.3 \mathrm{~J} / \mathrm{g}$, and 31.5 and $27.6 \mathrm{~J} / \mathrm{g}$, respectively. Basically, phase change enthalpy was supposed to be proportional to the content of the organic part within the phase change composites, then, 
the theoretical $\Delta H_{m}$ and $\Delta H_{c}$ of phase change for the above three were calculated to be 18.7 and $18.4 \mathrm{~J} / \mathrm{g}$ for LA/mFA, and 37.32 and $36.7 \mathrm{~J} / \mathrm{g}$ for the other two. The slightly lower $\Delta H$ in both melting and freezing processes can be explained as follows: due to the confining effect by solid matrix, part of the LA molecules could be trapped at the coarse surface, which lose the ability to participate the bulky melting and crystallization. Therefore, there is no contribution of the overall latent heat storage or release.

Regarding practical application, the thermal durability would become greatly important. Then, all three composites were subjected to 1000 thermal cycling to see if the phase change temperature or enthalpy would change. Figure 8a,b provided the DSC profiles before and after thermal cycling test, respectively. The supercooling phenomenon still existed. Moreover, the textural thermal factors were given in Table 3 . The $T_{m}$ and $T_{c}$ of LA/FA merely remained unchanged, however, the $\Delta H_{m}$ and $\Delta H_{c}$ was substantially dropped. More than a half was lost. This can be attributed to the weak adsorption capacity of FA toward organic LA, which arose from its relatively smooth surface. On the contrary, the $T_{m}$ and $T_{c}$ of LA/0.2 mFA and LA/0.4 mFA slightly increased, yet was still below $45^{\circ} \mathrm{C}$. More importantly, the $\Delta H_{m}$ and $\Delta H_{c}$ only showed maximum loss by $9.3 \%$ even after 1500 cycles, suggesting the excellent thermal stability. The rough surface created by molten salts etching should account for such excellent durability.
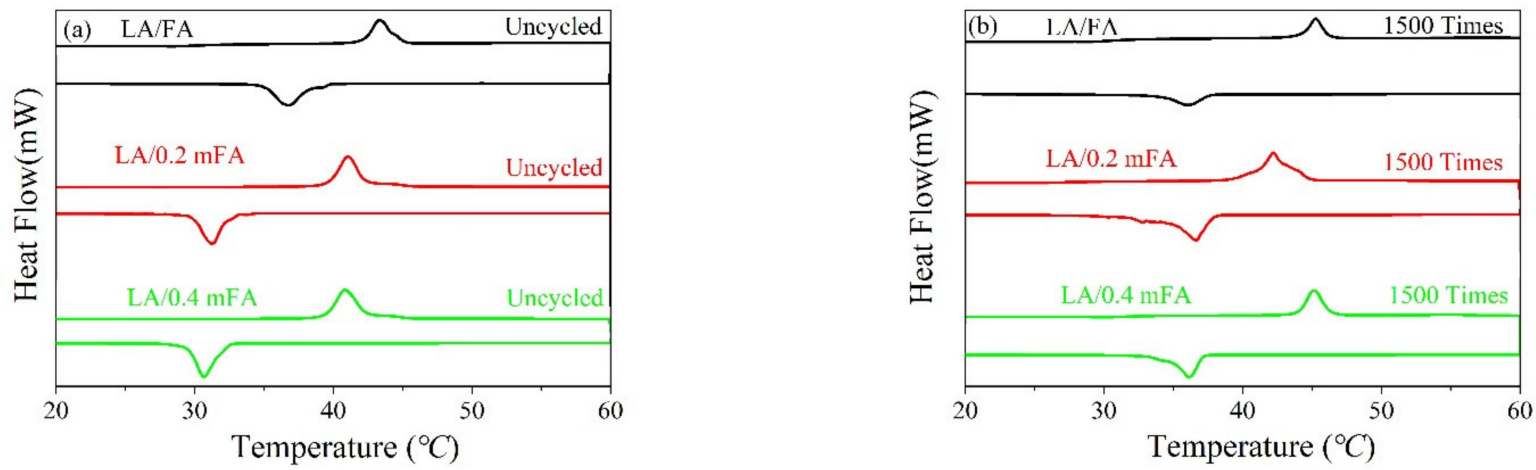

Figure 8. DSC curves of LA, LA/FA, LA/0.2 mFA, and LA/0.4 mFA: (a) before 1500 thermal cycles; (b) after 1500 thermal cycles.

Table 3. Textural thermal properties of LA/FA, LA/0.2 mFA and LA/0.4 mFA before and after 1500 thermal cycles.

\begin{tabular}{cccccc}
\hline \multirow{2}{*}{ PCM } & \multirow{2}{*}{ Cycles } & \multicolumn{2}{c}{ Heating Process } & \multicolumn{2}{c}{ Cooling Process } \\
& & $\boldsymbol{T}_{\boldsymbol{m}}\left({ }^{\circ} \mathrm{C}\right)$ & $\Delta \boldsymbol{H}_{\boldsymbol{m}}(\mathrm{J} / \mathrm{g})$ & $\boldsymbol{T}_{\boldsymbol{c}}\left({ }^{\circ} \mathrm{C}\right)$ & $\Delta \boldsymbol{H}_{\boldsymbol{c}}(\mathbf{J} / \mathbf{g})$ \\
\hline \multirow{2}{*}{ LA/FA } & 0 & 42.3 & 16.7 & 38.5 & 15.8 \\
& 1500 & 41.9 & 7.5 & 38.9 & 6.5 \\
LA/0.2 mFA & 0 & 39.5 & 34.1 & 32.1 & 31.3 \\
& 1500 & 40.8 & 32.3 & 37.6 & 28.4 \\
LA/0.4 mFA & 0 & 39.7 & 31.5 & 32.4 & 27.6 \\
& 1500 & 42.2 & 30.9 & 38.9 & 26.7 \\
\hline
\end{tabular}

\section{Conclusions}

In summary, we proposed the thermal treatment of FA with molten salt $\mathrm{Na}_{2} \mathrm{CO}_{3}$ to introduce significant surface roughness. When used as solid matrix for LA loading, the resultant exhibited doubled loading capacity of $20 \%$, which can be ascribed to strong adsorption effect by those surface grooves and gaps. Furthermore, the present phase change composites exhibited significantly enhanced thermal conductivity up to $0.5668 \mathrm{~W} / \mathrm{mK}$, due to the increased proportion of $\mathrm{Al}_{2} \mathrm{O}_{3}$ by etching effect. Meanwhile, the melting and crystalizing remained around that of pure LA and well located within the range from $30{ }^{\circ} \mathrm{C}$ to $45^{\circ} \mathrm{C}$. In addition to excellent working durability even after the 1500 thermal 
cycling test, the composite offered great promise for application in passive energy-saving building structures. The finding here may provide new insights for design guidance toward FA-based functional composites.

Author Contributions: Conceptualization, D.L. and M.C.; methodology, J.Y.; formal analysis, Y.Z.; investigation, D.L.; writing—original draft preparation, D.L.; writing—review and editing, D.L.; supervision, H.Y.; project administration, H.Y.; funding acquisition, H.Y., D.L. and Y.C. All authors have read and agreed to the published version of the manuscript.

Funding: This work is the financially supported by the Key-Area Research and Development Program of Guangdong Province (No. 2019B110209003), Science and Technology Project of Guangdong Province (No. 2016A020221025), Natural Science Foundation of Guangdong Province (No. 2019A1515011570), and Key Special Project for Introduced Talents Team of Southern Marine Science and Engineering Guangdong Laboratory (Guangzhou) (No. GML2019ZD0101). This research received no external funding.

Institutional Review Board Statement: Not applicable.

Informed Consent Statement: Not applicable.

Data Availability Statement: Accepted and complied with.

Conflicts of Interest: There are no conflicts to declare.

\section{References}

1. Li, J.; Zhang, S.; Wang, Q.; Ni, W.; Li, K.; Fu, P.; Hu, W.; Li, Z. Feasibility of using fly ash-slag-based binder for mine backfilling and its associated leaching risks. J. Hazard. Mater. 2020, 400, 123191. [CrossRef]

2. Sanjuán, M.Á.; Suárez-Navarro, J.A.; Argiz, C.; Mora, P. Assessment of natural radioactivity and radiation hazards owing to coal fly ash and natural pozzolan Portland cements. J. Radioanal. Nucl. Chem. 2020, 325, 381-390. [CrossRef]

3. Deng, C.; Jiang, Y.; Yuan, K.; Tian, T.; Yi, Y. Mechanical properties of vertical vibration compacted lime-fly ash-stabilized macadam material. Constr. Build. Mater. 2020, 251, 119089. [CrossRef]

4. Akeiber, H.; Nejat, P.; Majid, M.Z.A.; Wahid, M.A.; Jomehzadeh, F.; Zeynali Famileh, I.; Calautit, J.K.; Hughes, B.R.; Zaki, S.A. A review on phase change material (PCM) for sustainable passive cooling in building envelopes. Renew. Sustain. Energy Rev. 2016, 60, 1470-1497. [CrossRef]

5. $\mathrm{Hu}, \mathrm{H}$. Recent advances of polymeric phase change composites for flexible electronics and thermal energy storage system. Compos. Part B Eng. 2020, 195, 108094. [CrossRef]

6. Wen, R.; Zhang, X.; Huang, Z.; Fang, M.; Liu, Y.; Wu, X.; Min, X.; Gao, W.; Huang, S. Preparation and thermal properties of fatty acid/diatomite form-stable composite phase change material for thermal energy storage. Sol. Energy Mater. Sol. Cells 2018, 178, 273-279. [CrossRef]

7. Song, S.; Zhao, T.; Qiu, F.; Zhu, W.; Chen, T.; Guo, Y.; Zhang, Y.; Wang, Y.; Feng, R.; Liu, Y.; et al. Natural microtubule encapsulated phase change material with high thermal energy storage capacity. Energy 2019, 172, 1144-1150. [CrossRef]

8. Zhang, P.; Xiao, X.; Ma, Z.W. A review of the composite phase change materials: Fabrication, characterization, mathematical modeling and application to performance enhancement. Appl. Energy 2016, 165, 472-510. [CrossRef]

9. Hao, P.; Zhao, Z.; Leng, Y.; Tian, J.; Sang, Y.; Boughton, R.I.; Wong, C.P.; Liu, H.; Yang, B. Graphene-based nitrogen self-doped hierarchical porous carbon aerogels derived from chitosan for high performance supercapacitors. Nano Energy 2015, 15, 9-23. [CrossRef]

10. Kholmanov, I.; Kim, J.; Ou, E.; Ruoff, R.S.; Shi, L. Continuous Carbon Nanotube-Ultrathin Graphite Hybrid Foams for Increased Thermal Conductivity and Suppressed Subcooling in Composite Phase Change Materials. ACS Nano 2015, 9, 11699. [CrossRef]

11. Lv, P.; Liu, C.; Rao, Z. Experiment study on the thermal properties of paraffin/kaolin thermal energy storage form-stable phase change materials. Appl. Energy 2016, 182, 475-487. [CrossRef]

12. Karaipekli, A.; Biçer, A.; Sarı, A.; Tyagi, V.V. Thermal characteristics of expanded perlite/paraffin composite phase change material with enhanced thermal conductivity using carbon nanotubes. Energy Convers. Manag. 2017, 134, 373-381. [CrossRef]

13. Sarı, A.; Karaipekli, A. Preparation, thermal properties and thermal reliability of capric acid/expanded perlite composite for thermal energy storage. Mater. Chem. Phys. 2008, 109, 459-464. [CrossRef]

14. Wang, J.; Yang, M.; Lu, Y.; Jin, Z.; Tan, L.; Gao, H.; Fan, S.; Dong, W.; Wang, G. Surface functionalization engineering driven crystallization behavior of polyethylene glycol confined in mesoporous silica for shape-stabilized phase change materials. Nano Energy 2016, 19, 78-87. [CrossRef]

15. Sharma, R.K.; Ganesan, P.; Tyagi, V.V.; Metselaar, H.S.C.; Sandaran, S.C. Thermal properties and heat storage analysis of palmitic acid-TiO 2 composite as nano-enhanced organic phase change material (NEOPCM). Appl. Therm. Eng. 2016, 99, 1254-1262. [CrossRef] 
16. Yang, J.; Qi, G.-Q.; Liu, Y.; Bao, R.-Y.; Liu, Z.-Y.; Yang, W.; Xie, B.-H.; Yang, M.-B. Hybrid graphene aerogels/phase change material composites: Thermal conductivity, shape-stabilization and light-to-thermal energy storage. Carbon 2016, 100, 693-702. [CrossRef]

17. Ji, H.; Sellan, D.P.; Pettes, M.T.; Kong, X.; Ji, J.; Shi, L.; Ruoff, R.S. Enhanced thermal conductivity of phase change materials with ultrathin-graphite foams for thermal energy storage. Energy Environ. Sci. 2014, 7, 1185-1192. [CrossRef]

18. Qiu, F.; Li, S.K.S.D.N.; Liu, Y.; Wang, Y.Q.; Dong, L.J. Experimental investigation on improvement of latent heat and thermal conductivity of shape-stable phase-change materials using modified fly ash. J. Clean. Prod. 2020, 246, 118952. [CrossRef]

19. Zhang, X.; Zhang, T.; Yi, Z.; Yan, L.; Liu, S.; Yao, X.; Guo, A.; Liu, J.; Hou, F. Multiscale mullite fiber/whisker reinforced silica aerogel nanocomposites with enhanced compressive strength and thermal insulation performance. Ceram. Int. 2020, 46, 28561-28568. [CrossRef]

20. Pu, D.M.; Xiao, P.J.C.P.; Li, Z.; Deng, P.Y.; Pang, L.; Li, J.W.; Li, Y. Oxidation and thermal cycling behavior of c-AlPO4 and SiC whisker co-modified mullite deposited on SiC-C/SiC composites. Surf. Coat. Technol. 2020, 400, 126201. [CrossRef]

21. Liu, D.Z.; Han, K.X.G.W.B.; Wang, G. Fabrication and properties of three-directional orthogonal aluminosilicate fiber fabricreinforced mullite composite. Ceram. Int. 2020, 46, 23956-23963. [CrossRef]

22. Ma, J.; He, B.D.C.; Zeng, S.H.; Hua, K.H.; Xi, X.A.; Luo, B.Y.; Shui, A.Z.; Tian, W. Corrosion Resistance Properties of Porous Alumina-Mullite Ceramic Membrane Supports. Adv. Eng. Mater. 2020, 22, 1901442. [CrossRef]

23. Deshkar, A.; Youngman, O.G.R.E.; Mauroc, J.C.; Goel, A. Why does B2O3 suppress nepheline (NaAlSiO4) crystallization in sodium aluminosilicate glasses? Phys. Chem. Chem. Phys. 2020, 22, 8679. [CrossRef] [PubMed]

24. Shukla, R.; Yadav, S.K.G.H.; Ranjane, P.; Kadam, R.M.; Achary, S.N.; Tyagi, A.K. A carnegieite type red emitting NaAlSiO4:Eu3+ phosphor: Concentration dependent time resolved photoluminescence and Judd-Ofelt analysis. J. Lumin. 2019, 209, 283-290. [CrossRef]

25. Mahloujifar, M.M. Kaolinite fusion in carbonate media: KAlSiO4-NaAlSiO4 phase transformations and morphological study. Mater. Res. Express 2019, 6, 025040. [CrossRef]

26. Zhao, M.; Molokeev, Z.G.X.M.S.; Ning, L.X.; Liu, Q.L. Temperature and Eu2+-Doping Induced Phase Selection in NaAlSiO4 Polymorphs and the Controlled Yellow/Blue Emission. Chem. Mater. 2017, 29, 6552-6559. [CrossRef]

27. Deshkar, A.; Southern, J.M.S.A.; Kobera, L.; Bryce, D.L.; McCloy, J.S.; Goel, A. Understanding the structural origin of crystalline phase transformations in nepheline (NaAlSiO4)-based glass-ceramics. J. Am. Ceram. Soc. 2017, 100, 2859-2878. [CrossRef]

28. Konuklu, Y.; Ersoy, O. Fabrication and characterization of form-stable phase change material/xonotlite microcomposites. Sol. Energy Mater. Sol. Cells 2017, 168, 130-135. [CrossRef]

29. Mu, S.Y.; Zhang, J.G.B.; Qi, S.W.; Yang, L.J.; Wang, D.; Zhang, S.; Yu, Y. On Preparation and Characterization of the Phase Change Nanofibers From the Copolymer of Poly(styrene-co-acrylonitrile) and Lauric Acid. J. Macromol. Sci. 2015, 52, 699-706. [CrossRef]

30. Liang, K.; Zhang, L.S.J.Y.; Cheng, J.; Wang, X.D. Fabrication of shape-stable composite phase change materials based on lauric acid and graphene/graphene oxide complex aerogels for enhancement of thermal energy storage and electrical conduction. Thermochim. Acta 2018, 664, 1-15. [CrossRef]

31. Liu, S.Y.; Wang, J.H.L.N.; Gao, Y.; Sun, H.; Li, W.L. A lauric acid-hybridized bentonite composite phase-changing material for thermal energy storage. RSC Adv. 2020, 10, 25864. [CrossRef]

32. Wu, J.Q.; Xu, D.L.W.X.M.; Long, N.B.; Zhang, R.F. Efficient synthesis of DHA/EPA-rich phosphatidylcholine by inhibition of hydrolysis reaction using immobilized phospholipase A1 on macroporous SiO2/cationic polymer nano-composited support. Mol. Catal. 2021, 499, 111278. [CrossRef]

33. Belgibayeva, A.; Taniguchi, I. Insights into the improved electrochemical performance of lithium-sulfur battery with free-standing $\mathrm{SiO} 2 / C$ composite nanofiber mat interlayer. J. Power Sources 2021, 484, 229308. [CrossRef]

34. Belgibayeva, A.; Taniguchi, I. Synthesis and characterization of $\mathrm{SiO} 2 / \mathrm{C}$ composite nanofibers as free-standing anode materials for Li-ion batteries. Electrochim. Acta 2019, 328, 135101. [CrossRef]

35. Ma, J.H.; Zhou, Y.Y.L.X.R.; Yang, X.Y.; Alharthi, F.A.; Alghamdi, A.A.; Cheng, X.W.; Deng, Y.H. Au Nanoparticles Decorated Mesoporous SiO2-WO3 Hybrid Materials with Improved Pore Connectivity for Ultratrace Ethanol Detection at Low Operating Temperature. Small 2020, 16, 2004772. [CrossRef]

36. Garcia-Garcia, F.J.; Yubero, J.G.-R.F.; Espinos, J.P.; Gonzalez-Elipe, A.R. “In Operando” X-ray Absorption Spectroscopy Analysis of Structural Changes During Electrochemical Cycling of WO3 and WxSiyOz Amorphous Electrochromic Thin Film Cathodes. J. Phys. Chem. C 2015, 119, 644-652. [CrossRef]

37. Yang, L.; Zhang, Y.P.Y.N.; Dong, Y.F.; Sun, Y.F.; Ji, W.H. Photo-to-thermal conversion and energy storage of lauric acid/expanded graphite composite phase change materials. Int. J. Energy Res. 2020, 44, 8555-8566. [CrossRef]

38. Blohm, S.; Heinze, T. Mechanistic Considerations of Efficient Esterification of Starch with Propionic Anhydride/Lauric Acid in the Green Solvent Imidazole. Macromol. Chem. Phys. 2020, 221, 2000264. [CrossRef]

39. Hirlekar, S.; Aswal, D.R.V.K.; Prabhune, A.A.; Nisal, A. Lauric Acid Sophorolipid: Accelerating the Gelation of Silk Fibroin. ACS Omega 2020, 5, 28571-28578. [CrossRef]

40. Chinnasamy, V.; Appukuttan, S. Preparation and thermal properties of lauric acid/myristyl alcohol as a novel binary eutectic phase change material for indoor thermal comfort. Energy Storage 2019, 1, e80. [CrossRef] 